\title{
SMALL ANGLE: X-RAY SCATTERING FROM COAL-DERIVED LIQUIDS
}

\author{
BENEDICT HO* and DAEE E. BRIGGS
}

Department of Chenuical Engineering. Unicersity of Michigan, Amu Arbor, MII 48109 (U.S.A.)

(Received December 30 th, 1981 ; accepted January 4 th, 1982)

\begin{abstract}
Small angle $X$ ray scattering measurements were used to determine the size and shaje of asphaltene and preasphaltene miceltes in solution. The fraction of the coal-derivad Itquids forming micotles in solution was as high as 49\%. The fraetion depends upon the concentration and molecular size of the asphaltenes and preasphaltenes, the a- $a$ and/or hydrogen bonding properties of the solvent and the agitation. Most systems studied were polydispersed with the majority of the micelles being spherical with a diameter of 22-38 A. Micelles in the 80-100 A range were also apparent but at $5-12 \%$ of the number of th is smaller size. Variations in the scattering intensity over the scattering angles and the variations of the absolute intensity of seattered $X$-rays from solutions irradiated immediately after ultrasonic agitation and upon extended sitting, suggested the presence of a low tevel toe in most of the solutions.
\end{abstract}

\section{INTKODUCT'LON}

Coal-derived liquids are complex mixtures of liquid and semi-liquid constituents. They can be broudly classified as oils, resins, asphaltones and preasphaltenes. Oils and resins are nominally soluble in gentane, asphaltenes are insoluble in pontane but soluble in benzene or toluene and preasphaltenes are insoluble in toluene but soluble in tetrahydrofurun (THF) or pyridine. The molecular weight, number of condensed aromatic rings, the number of nitrogen, oxyten and sulfur he teroatoms and the concentration of metals increases in going from the average molecule in the oil fraction to the average molecule in the preasphaltene iraction [1]. Most of the oxygen in the asphaltene and preasphaltene fractions is phenolic oxygen and most of the nitrogen is basic ring nitrogen.

The physical state of coal-dnrived liquids depends significantly on the relative amounts of each fraction. Anomalies are observed when coal liquefaction slurries containing high levels of asphaltenes and preasphaltenes are fiticered in the $200-320^{\circ} \mathrm{C}$ temperaturu range [2]. The gnomalies have becn attri-

\footnotetext{
*Current address: AMOCO Production, Tulsa, Oklahoma.
} 
buted to the presence or formation of colloidal-size particles and flocs in the system.

Culloidal-size particles can form from the association of asphaltene and preasphaltene molecules through $\pi-\pi$ and hydrogen bonding. Snyder [3] showed that the free energy of adsorption, $\Delta G$, for adsorption of aromatic arnines from pentane onto water-deactivated alumina was a linear function of the number of $\pi$ electrons when the amino group was in the position of minimum steric hindrance. Therefore strong attractive forces would be expected to exist between molecules in the asphaltene and preasphaltene fractions. These forces could result in intermolecular associations in the $200-320^{\circ} \mathrm{C}$ temperature range. Differences in molecular structure between associated molecules can produce a residual attraction for other molecules. Depending upon the magnitude of the residuril attractive force, three or four poly aromatic molecules could associate into a stacked arrangement to form a nominally spherical colloidal size particle. Pyridine and phenol can associate through $\pi-\pi$ bonding and hydrogen bonding in the orientation illustrated in Fig. 1 . The association results in a residual dipole and the associated pair is not precluded from further association, although the force for association would be less. Associations as illustrased in Fig. 2 would be expected.

An attractive force to a lesser extent is the London-Van der Waals electromagnetic (cohesion) force. This force becomes more significant between particles and clusters as the attraction between atom pairs is additive. The summation leads not only to a total larger force hut also to a less rapid decay with increasing distance of separation. Although London-Van der Waals forces would not be expected to cause mole-ular associations, they could cause associations between colloidal-size particles of the type illustrated in Fig. 2.
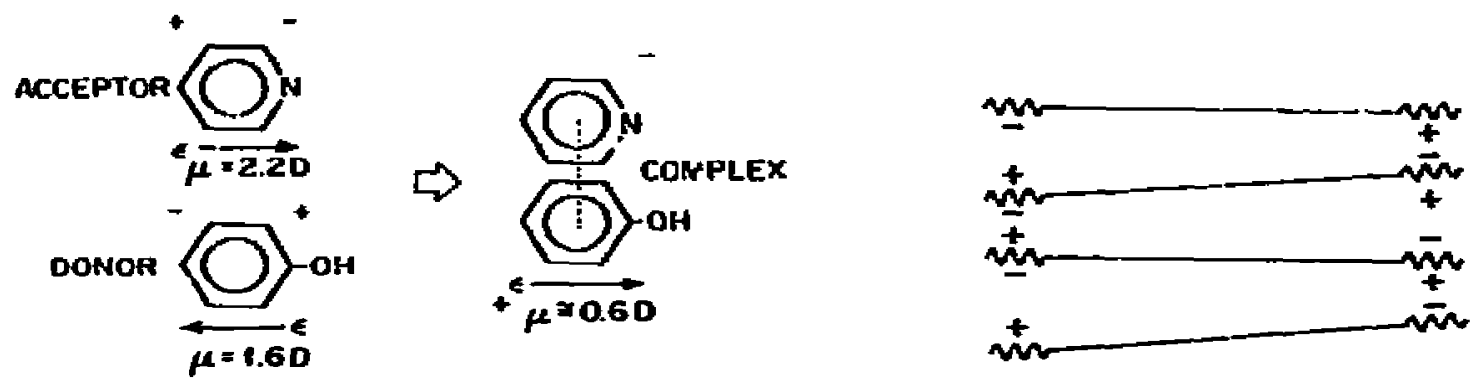

Fig. 1. Illustration of $n-\pi$ bonding betwean phenol and pyridine.

Fig. 2. Ideal stacking arrangement for aromatic sheets into a nominally spherical micelle.

In addition to possible electrostetic repulsions which result from certain orientations of molecules with respect to each other, two other repulsive forces exist in coal-derived liquids. These forces inhibit intermolecular association and promote stability to those colloidal particles that do form. Entropic repulston (steric hindrance) is associated with lcng chain groups 
substituted into the principal molecular structure. When molecules or particles with long chains approach, the steric hindrance greatly limits freedom of movement of the projecting chains and limits the dist ince of approach between rnolecules. Alkyl groups are common in the aromatic structure of coal-deriv:ad liquids. Solvation repulsion arises with approaching molecules, or particlus "squeeze out" the solvent molecules between them. When the solvent is polar or contains a high concentration of polas compounds, coagulation of particles or association of molecules beco nes less probable because niore energy must be expended to "squeeze out" the solvent. Resins and low molecular asphaltenes would be expected to limit associations between esphaltenes and would promote stability of eny colloidal particles that did form.

The small angle $X$-ray technique was selected to study the physical state of selected fractions of coal-derited liquids when dissolved or dispersed in different solvents. The technique is particularly effective for the size of the colloidal particles explected in the system studied. Unfortunately, the method has some limitations. Whert particles $>1000 \Omega$ exist or form in the system, Mie scattering attenuates the $X$-ray signal and produces a periodicity in the $X$-ray intensity in the smali angle range of interest. Multiple scattering can cause $\mathbf{X}$-ray attenuation when the concentration of scattering particles becomes large. An underestimate of the colloidal system results. Although it is possible to design and operate a small $\mathbf{X}$-ray cell at elevated pressures and temperatures, it is extremely difficult. A small angle $X$-ray cell was constructed to examine samples at $70^{\circ} \mathrm{F}$. Sample concentrations were selected to avoid or minimize multiple scattering.

\section{SAMIPLE PREPARATION}

Coal-derived liquicls from the vacuum bottoms produced from the liquefaction of an Illinois $\mathrm{N} r, 6$ coal in the $\mathrm{H}$-Coal process were separated into four fractions by seque ntial batch solvent extractions. Tite extracts were separated from the residue by filtration through Whatmsn No. $42(2 \mathrm{~mm}$ pore size) paper. Detaili on the extraction procedure, the method of solvent removal and the analy,ical methods mentioned below ant given in ref. 4. Using pentane, a mixture of 75 vol.\% pentane/25 vol.\% toluene, toluene and THF, the vacuum bottoms were separated into pentane-soluble oils and resins, pentane-insoluble, 75 vol. $\%$ pentane/25 vol.\% toluane-soluble lovt molecular weight asphaltenes, 75 vol.\% pentane/25 vol.s toluene-insoluble, toluene-soluble high molecular weight asphaltenes, and toluene-insoluble, THF soluble preasphiltenes. The high molecular weight asphaltenes and preasphaltenes were referred to as TS and IHF material, respectively. The TS material was further fractioned by preparative gel permeation chromatography (GPC) into five fractions. The column packing was $8 \%$ divinylbenzenestyrene copolymer and THF was the eluting solvent. The first fraction eluted from the GPC column was labeled GPC-1 and the fifth fraction GPC-5. 
Each sample was analyzed by microcombustion analysis to determine the weight fercent carbon, hydrogen, nitrogen and sulfur. Oxygen was determined by difference. The samples were also analyzed by neutron activation analysis to determine the concentration of those metals which can be determined by intermediate irradiation times. Proton NMR was used to determine the ratio of aliphatic hydrogen to aromatic hydrogen. The results of the analyses are presented in Table 1 . The TS fraction was found to contain a higher than expected level of metals. A portion of the material was dissolved in THF and fittered through Whatman No. 42 paper to produce the Tsf fraction. Molecular weights were measured with a vapor pressure osmometer using pyridine at $75^{\circ} \mathrm{C}$.

The number of carbon, hydrogen, nitrogen, oxygen and sulfur atoms in the "average" molecule of each fraction was estimated using the molecular weights and elemental analyses. When these numbers are taken in conjunction with the proton NMR results, differences between the fractions become readily apparent.

Although the neutron activation analyses are not very quantitative, these and other analyzes [1] show that GPC fractionation removes a substantial amount of the metals retained in the fractions isolated by solvent extraction. Those metals retained in the GPC frartions could be in organometallic molecules, as distinct mineral particles of the same approximate size as the mole-

TABLE 1

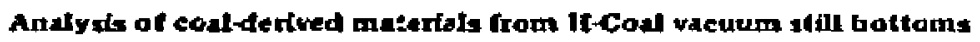

\begin{tabular}{|c|c|c|c|c|c|c|c|c|c|c|c|c|c|}
\hline \multirow[t]{2}{*}{ Sample } & \multirow{2}{*}{ Wt. } & \multirow{2}{*}{$\begin{array}{l}\text { aral. } \\
\text { wt. }\end{array}$} & \multicolumn{4}{|c|}{ Weitht percent } & \multirow[b]{2}{*}{$\mathbf{s}$} & \multicolumn{5}{|c|}{ Acoms in averate motecute } & \multirow{2}{*}{$\begin{array}{l}\text { Har } \\
\text { Har }\end{array}$} \\
\hline & & & $\boldsymbol{c}$ & $\mathbf{H}$ & $\mathbf{N}$ & $\boldsymbol{\sigma}^{\mathbf{b}}$ & & $\mathbf{c}$ & II & $\mathbf{N}$ & $\mathbf{0}$ & $\mathbf{s}$ & \\
\hline $\begin{array}{l}\text { Ts" } \\
\text { Tyt } \\
\text { THE } \\
\text { apc-1 } \\
\text { apc-2 } \\
\text { GRc-3 } \\
\text { GPC-4 } \\
\text { GPC-s }\end{array}$ & $\begin{array}{l}0.172 \\
0.179 \\
0.165 \\
0.198 \\
0.325\end{array}$ & $\begin{array}{l}699 \\
670 \\
685 \\
663 \\
584 \\
401 \\
280 \\
324\end{array}$ & $\begin{array}{r}87.50 \\
69.20 \\
44.09 \\
84.29 \\
85.36 \\
86.41 \\
87.87 \\
86.36\end{array}$ & $\begin{array}{l}6.30 \\
6.38 \\
6.11 \\
6.95 \\
7.08 \\
7.52 \\
7.59 \\
7.90\end{array}$ & $\begin{array}{l}1.17 \\
1.27 \\
1.74 \\
1.74 \\
1.79 \\
1.17 \\
1.10 \\
0.71\end{array}$ & $\begin{array}{r}1.96 \\
3.47 \\
6.96 \\
6.44 \\
5.45 \\
+.18 \\
3.11 \\
4.91\end{array}$ & $\begin{array}{l}3.17 \\
0.66 \\
1.06 \\
0.96 \\
0.82 \\
0.72 \\
0.33 \\
0.19\end{array}$ & $\begin{array}{r}+2.51 \\
62.23 \\
46.67 \\
11.8 .4 \\
28.88 \\
20.94 \\
15.97\end{array}$ & $\begin{array}{r}36.86 \\
64.26 \\
46.08 \\
41.63 \\
30.16 \\
71.74 \\
17.64\end{array}$ & $\begin{array}{l}0.51 \\
1.10 \\
0.64 \\
0.54 \\
0.34 \\
0.28 \\
0.11\end{array}$ & $\begin{array}{l}1.25 \\
3.87 \\
2.67 \\
2.00 \\
1.05 \\
0.06 \\
0.64\end{array}$ & $\begin{array}{l}0.12 \\
0.30 \\
0.20 \\
0.15 \\
0.09 \\
0.03 \\
0.01\end{array}$ & $\begin{array}{l}2.7 \\
1.8 \\
1.4 \\
7.6 \\
3.1 \\
2.8 \\
2.5 \\
0.9\end{array}$ \\
\hline yerc & 1.000 & $\tan$ & & & & & & & & & & & \\
\hline
\end{tabular}

Metats contents from atitron activation analysict-ppm by we."

\begin{tabular}{|c|c|c|c|c|c|c|c|c|}
\hline & Al & $\mathbf{C a}$ & $\mathbf{c t}$ & Me & Mnt & $N_{a}$ & $\mathbf{x} \mathbf{i}$ & $v$ \\
\hline $\begin{array}{l}\text { TS } \\
\text { APC-1 } \\
\text { GRC-2 } \\
\text { GPC-3 } \\
\text { GPC-4 } \\
\text { GPC-6 }\end{array}$ & $\begin{array}{r}1921.49 \\
57.1 \\
23.8 \\
<\quad 10.3 \\
<\quad 12.2 \\
<\quad 10.3\end{array}$ & $\begin{array}{r}5307.0 \\
<78.2 \\
<75.7 \\
<83.9 \\
<258.8 \\
<\quad 76.3\end{array}$ & $\begin{array}{l}921.5 \\
188.3 \\
153.1 \\
119.6 \\
156.9 \\
188.0\end{array}$ & $\begin{array}{r}2103.8 \\
<189.2 \\
<164.9 \\
<478.7 \\
<187.7 \\
<143.0\end{array}$ & $\begin{array}{r}103.2 \\
26.8 \\
17.3 \\
5.4 \\
<1.5 \\
<1.0\end{array}$ & $\begin{array}{r}1479.9 \\
75.9 \\
40.7 \\
39.4 \\
<26.3 \\
<14.3\end{array}$ & $\begin{array}{r}1286.3 \\
250.5 \\
130.1 \\
<62.4 \\
<76.7 \\
<46.7\end{array}$ & $\begin{array}{r}99.4 \\
2.2 \\
1.2 \\
0.3 \\
0.3 \\
<0.2\end{array}$ \\
\hline
\end{tabular}

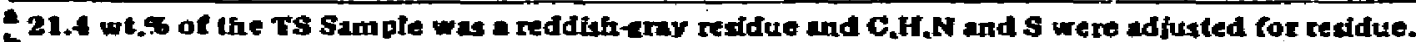

b Determined by difference.

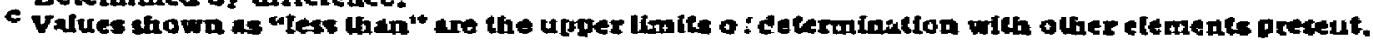


cules in the GPC fractions eluted or colloidal-size mineral particles which are associated with polyaromatic molecules in the GPC fractions. The reduction is least for manganese and titanium. It is common to see titanium retained in the asphaltene and prezsphaltene fractions.

\section{X-RAY METHODS}

\section{Equipment}

The apparatus consisted of an X-ray tube and generator, a gonimeter, a sample cell and a detector. The $X$-ray tube was a Philips copper target microfocus tube (No. 34048) with a beryllium-mica window having a line focus of $0.1 \times 10 \mathrm{~mm}$. $\Lambda 0.06 \mathrm{~mm}$ thick nickel filter was used as a $K_{g}$ filter. The generator was uperated at $40 \mathrm{KV}$ and $25 \mathrm{~mA}$. It had a current stability of $\pm 0.05 \%$.
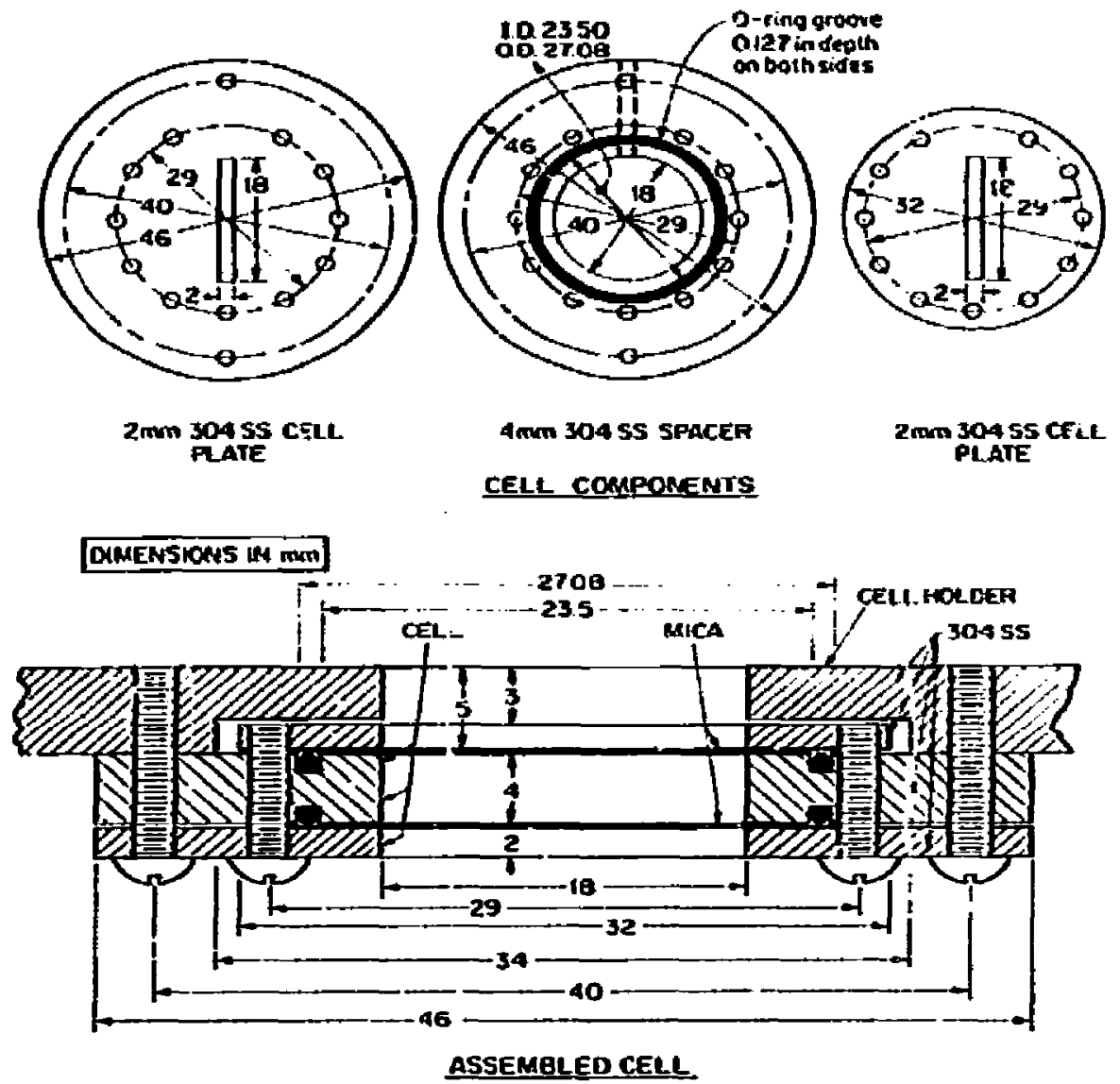

Fig. 3. Component parts and crosstection of amall angle $X$.ray scatiering cell. 
The goniometer was an automated Rigaku-Denki low angle unit with five slit collimators. The step-scanning controller moved the counter bench is specified two theta scattering angle steps up to a maximum diffracted beam of $10^{\circ}$. Stepping in both + and - directions was possible.

A schematic drawing of the sample cell is presented in Fig. 3. The cell was constructed of type 304 stainless steel. Two Viton-A O-rings were placed on both sides of the 4-mm thick center spacer. The $O$-rings were seated on the two 0.06-mm thick mica windows forming an appruximately $1.0 \mathrm{ml}$ cavity. The cavity was filled with a hypouermic syringe through one of two small holes at the top of the center spacer.

Two detector systems were used in the study. Most of the data were taken on a system consisting of a Hewlett Packard Model 5580 A NIM power supply, Model 5554 A preamplifier, Model 5582 A linear amplifier, Model 5583 A single channel analyzer and a Model 5690 A scaler-timer. A Harshaw N-780 log/linear ratemeter and a Harrison $6: 10$ A D.C. power supply were also a part of the system. The X-ray beam at the cell was $0.1 \times 10 \mathrm{~mm}$. The tine to obtain 5000 counts at each step increment was automatically secorded. Ccunting was initiated at $0.1^{\circ}$ and run to $2^{\circ}$ in $0.05^{\circ}$ intervals.

The second detector used was a Tennelec Model PSD-110 linear position sensitive gas flow proportional counter. A mixture of $10 \%$ methane in arzon was supplied to the detector via a Tennelee GR-1000 gas regulator. The $X$-ray beam at the cell was $0.1 \times 6.35 \mathrm{~mm}$. The system was run for $1 \mathrm{~h}$ and the counts at each position accumulated in the 40 -channel memory.

\section{Corrections}

The measured intensity of the scattered $\mathbf{X}$-rays were corrected for barkground intensity. This included a correction for scatter from the $X$-ray collimation slits, from air in the region of the sample which was not evacuated, from the mica windows in the sample holder and from the solvent or mixtures of solvents. The method of Hendricks and $3 c h m i d t[5,6]$ was used to estimate the collimation correction. Background data ware obtained with the empty sample cell in place and with solvent or solvents in the cell to provide data for the other corrections.

\section{Methods of datu analysis}

After the collimation and the background corrections are made to the measired intensity, the corrected $X$-ray intensity, I(S), at the radial coordinate position, $S=2 \sin \theta / \lambda$ is obtained. $I(S)$ represents the intensity attributed to the asphaltenes and preasphaltenes in the sample. The scattering angle is $2 \theta$ and the $X$-ray wavelength is $X=1.54 \mathrm{~A}$. The data were analyzed for size distribution, volume fraction of the asphaltenes and preasphaltenes which were scattering and molecular weight of the scattering units. 
Particle size for a monodisperse system

At scattering angles less than $3^{\circ}$, the Guinier [7] approximation for the intensity of the scattered X-ray is given by

$$
I(S)=N\left(\Delta \rho_{0}\right)^{2} V^{2} \exp \left[-(4 / 3) \pi^{2} R^{2} S^{2}\right)
$$

where $N$ is the number of scatterers, $\left(\Delta \rho_{0}\right)^{2}$ is the electron density difference between the scatterers and the surroundings and $V$ is the volume of the scattere,$R$ is the average rudius of gyration of the particte. $R$ is defined as the root inean square of the distances of atoms from the center of gravity of the particle, each distance being modified by a coefficient equal to the at imic number of the atom. By plotting In $I(S)$ versus $S^{2}$ the Guinier [7] scattering plot is obtained. If the data can be correlateri well with a straight line, then the syste:n is a monodisperse system and th: radius of gyration of the particle can he obtained from the Guinier scattering plot. If the particle is assumed to be spherical the diameter of the partidle, $d$, can be estimated according to Beeman [8] from

$d=2 \sqrt{(5 / 3) R^{2}}$

Particle size distribution for a polydisperse syste $n$

If the Ciuinier scattering plot is curved, the system is a polydisperse system. The intensity of $X$-rays acattercd from a polydisperse system is the sum of the intensities of scattered $X$-rays for the different groups of particles. The intensity of scattered radiation $[7,9]$ as a function of $S$ is given by:

$$
I(S)=B \quad \bar{\int}_{0} W(R) R^{3} \exp \left[-(4 / 3) \pi^{2} R^{2} S^{2}\right] d R
$$

where $B$ is a proportionality constant and $W(R)$ is the weight fraction of the radius of gyration $R$. To determine the size distribution from observed intensity data the integral must be inverted. Similarly, the total intensity of the X-rays scattered by an isotropic system of particles of the same shape but different characteristic dimension, $d$, is a function of the radial coordinate in reciprocal space, $S$. When multiple scattering can be neglected, the relationship between the total intensity and $S$ can be expressed as an integral over the particle size range in which the distribution function, $D(d)$, is multiplied by a common single-particle scattering function of $S(d)$ which can ba calculated for the assumed particle shape. The particle size estimate results from a trial-and-error procedure with adjustments made to the size cistribution until the sum of the squared deviations is minimized. Vonk [10] developed the procedure and prepared a computer prcgiam to do the calculations. Vonk macle the program available for this research.

An example of the corrected observed iniensity if scattered $X$-rays frois a polydisperse system is illustrated in Fig. 4. The scat:er in the data as $S^{2}>1 \times 10^{-4} \mathrm{~A}^{-2}$ is attributable to Mie scattering. Tre particle-size distribution for tl:e system was obtained from the Vonk program and is presented in Fig. 5. The number distribution data are normalized to 1.0 for the size 

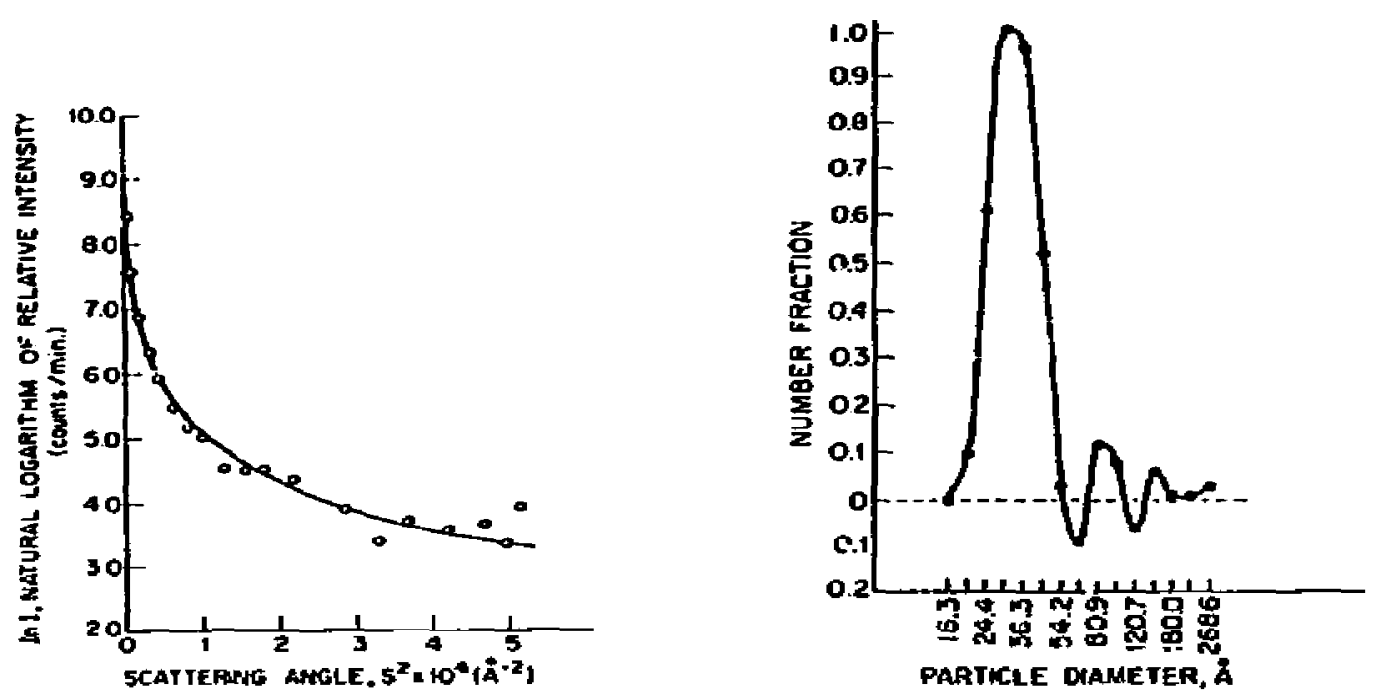

Fig- 4. Scatteriag intensity of coluene solutle, $76 \%$ pentante/25\% toluene-in oluble asphaltenes in inixture of 90 wi. $\%$ tetralin, 2.5 wt.9 m-cresol and 7.5 wk. $\%$ r-picoline at a concentration of + wt. $\%$ at $70^{\circ} \mathrm{F}$.

Fig. 5. Particle size distribution plat of a $100 \%$ toluene-golubte, 75 vol. $\%$ pentane/25 vol. $\%$ toluene-insoluble asphaltenes at a concentration of $10 \mathrm{wt} .5$ in a mixture of $90 \mathrm{wt.5}$ tetralin, 2.5 wt. $\%$ m-eresol and 7.6 wt. $\%$ r-picoline at 70'F.

most frequent in the system. The particles were best afproximated as spheres as were all the small angle scattered $X$-ray data in this study. The correlation coefficient ranged from 0.8 to 0.9 . The negative numbers in Fig. 5 are artifacts of the Vonk program and result in part from the Mie scattering by large particles or a floc produced by gggregation of smaller particles. This can also be attributed to the fact that the particles are not absolutely spherical.

Volume fraction of the sample scattering

The volume fraction of a sample scattering $X$-rays, $\Delta V / V$, was estimated from the total integrated corrected intensity in relation to the primary beam intensity, $I_{0}$, per volume irradiated using the method of Kratky [11]. The ratio of $I(S)$ to $I_{0}$ is defined as $I^{\prime}(S)$ and

$Q_{0}=\int_{0} S^{2} I^{i}(S) d S=\frac{\left(\Delta \rho_{0}\right)^{2}}{4} \frac{\Delta V}{V}$

The evaluation o: $Q_{0}$ was carried out by the numerical integration of the function. $\Delta \rho_{0}$ is the excess electron density difference between the sample that is scattering and the solvent. The electron density of the coal-derived materials was taken as 0.5 electrons per $A^{3}$. The electron density for amorphous carbon is from 0.5 to 0.6 electrons per $\mathrm{A}^{3}$. The absoluts intensity was measured by using a calibration sample (Lupolen No. 16/12) provided by Kratky [12]. 
Molecular weights

The molecular weights of the samples forming nominally monodisperse sy:3tems were estimated from the absolute intensity and the relative intensity at zero angle for each sample by the method of Kratky [12].

\section{RESULTS}

several of the small angle X-ray measurements of Ho [4] are presented. The data were selected to give some perspective on the differences between various coal-derived liquid fractions in solution and the effect of the solvent and concentration of the fraction in a solvent on the nature of the fraction in solution.

Model compound studies were effected by Ho [4] with o-phenylphenol (MW = 170) and quinoline (MW = 129) to estimate the lower limit of significant small angle scatter by molecules that associate. When equal molar ratios of $o$-phenylphenol and quinoline were dissoived in tetzalin, carbon tetrachloride and heptane to give concentrations from 1 to 5 wt. $\%$, no appreciablr. excess intensity values could be obtained between the 0 .phenylphenol and quinoline in the solvents and the solvents. This suggests that the lower molecular weight limit for significant. scatter is at loast 300.

\section{Coal-derived liquid fractions in pyridine}

Small angle $X$-ray scattering data for the high molecular weight aspahltene (TS) and preasphaltene (THF) fractions in pyridine at a concentration of 10 wt. .5 are presented in Fig. 6 . Both fractions result in polydispersed systems. As expected, rore scatior results from the THF fraction. The high intensity from the TS fraction at the smallest angle indicutes the presence of more large particles in the TS fraction than in the THF fraetion. This is not surprising as the analysis of the TS fraction indicated the presence of mineral matte: The intensity from the TS filtered material, the Tsf fraction, and a filtered Tsf fraction were considerably less but still indicated the presence of polydispersed systems.

The four sets of data in Fig. 6 were analyzed using the Vonk computer program and the particle size distribation data are given in Table 2. The fraction of the irradiated volume scattering $X$-rays was computed from the integrated intensity and the fraction of the coal-derived material scattering $\mathbf{X}$-ray was computed on the assumption that only associated coal-derived molecules are scattering $X$-rays. Statisizally, the particles are best described as spherical particles. In each sample, three distinct peaks occured in the particle size distribution. The most prominent particle size was the smallest, the particle diameter being approximately $33 \AA$. The second peak occurred at approximately 89 A with the number of particles being roughly $10 \%$ of the smaller size. The size of the largest particles ranged from 147 to 220 A in the four fractions. Consistent with the shapes of the relative intensity 


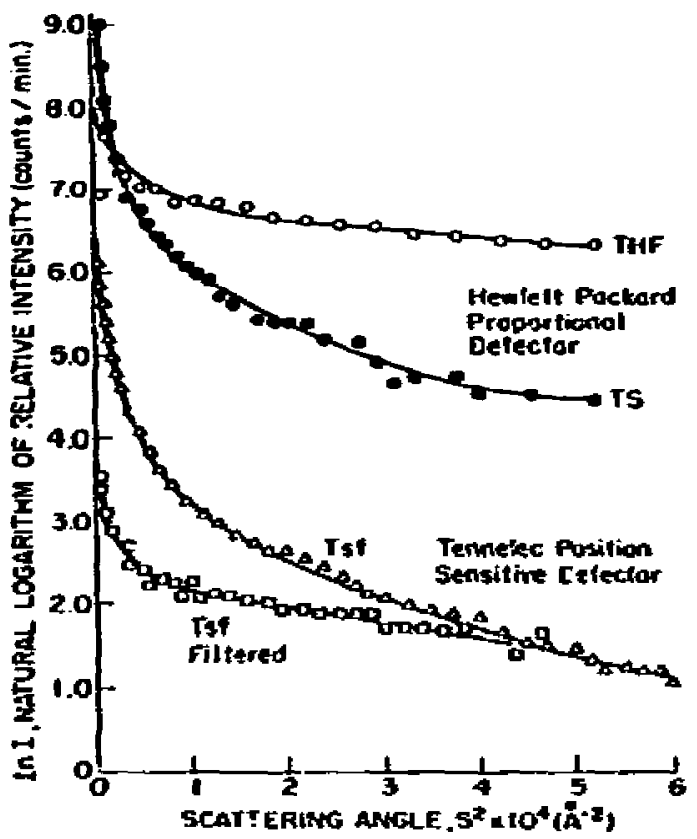

Fig. 6. Coal-derived liquid fractions at a concentration of 10 wt.\% in pyridine at $70^{\circ} \mathrm{F}$.

\section{TABLE 2}

Small angle X-ray scattering results for coal-derivetl tiquid tracitons a pyridine at a conentration of 10 wt. $\%$ at $70^{\circ} \mathrm{F}$

\begin{tabular}{|c|c|c|c|c|}
\hline Satuple & THF & TS & Psf & Tst-f \\
\hline $\begin{array}{l}\text { Size } 1 \text { particle diam. } A \\
\text { No. particles size } 1 / \text { No. size } 1\end{array}$ & $\begin{array}{r}32.5 \\
1.0\end{array}$ & $\begin{array}{r}29.8 \\
1.0\end{array}$ & $\begin{array}{r}32.9 \\
1.0\end{array}$ & $\begin{array}{r}36.3 \\
1.0\end{array}$ \\
\hline $\begin{array}{l}\text { Size } 2 \text { particle diam. }- \text { A } \\
\text { ro. particles size } 2 / \text { No. size } 1\end{array}$ & $\underset{0.110}{89.4}$ & 80.9 & $\stackrel{89.4}{0.186}$ & $\begin{array}{l}98.8 \\
0.098\end{array}$ \\
\hline $\begin{array}{l}\text { Sirs: } 3 \text { particle diam. }-\lambda \\
\text { No partictes stze } 3 / \text { No. sixe } 1\end{array}$ & $\begin{array}{r}15.3 .4 \\
0.01\end{array}$ & $\begin{array}{l}219.9 \\
0.060\end{array}$ & $\begin{array}{l}162.9 \\
0.060\end{array}$ & $\begin{array}{l}147.4 \\
0.014\end{array}$ \\
\hline Jafegrated intensity, $Q_{\bullet}+10^{*}$ & 24.5 & 12.8 & 3.9 & $\mathbf{3 . 4 3}$ \\
\hline Vol. fraction scattering. $\left(\Delta V / V ; \cdot 10^{2}\right.$ & 3.895 & 2.200 & 0.0988 & 0.0869 \\
\hline $\begin{array}{l}\text { Fraction of coal-derived } \\
\text { maicrial scattering } X \text { ray } \\
\text { based on } 8 \text { vol. } 96 \text { in } \\
\text { pyidine }\end{array}$ & 0.487 & 0.276 & 0.012 & 0.011 \\
\hline
\end{tabular}

curves, relatively more large particles were present in the TS and Tsf gamples.

Based on the coal-derived material occupying $8 \%$ of irradiated volume, 49 $A$ of the prasphaltene material was present as associated molecules. As expected, the fraction in the associated state drops off to $28 \%$ for the TS fraction and to $1 \%$ when the TS fraction is fittered once or twice. 
GPC-fractionated asphaltenes in pyridine and in a mixture

The TS fraction was fractionated by GPC to give five fractions with a more narrow range of molecular sizes than the TS fraction. Scattering data for the five fractions in pyridine and in a mixture of solvents at a concentration of 10 wt.\% are presented in Figs. 7 and 8 . The analysis of the scattering data is given in Table 3 .

When dispersed in pyridine, the five fractions formed monodispersed systems. Using Guinie-'s approximation the size of the scattering particles was estimnted to be about $22 \AA$ in the solutions containing the GPC-4 and GPC-5 fractions and $38 \mathrm{~A}$ in the solution containing GPC-1. As GPC-1 contains an aliphatic to aromatic hydrogen ratio of 3.6 , the presence of alkyl side chains and the larger molecular weight would attribute to the large particle size in that fraction. The variation in the fraction of the GPC sample scattering is roughly the same as it is in Table 2 for the coal-derived liquid fractions. GPC-1 is similar to preasphaitenes and GPC-5 is similar to the Tsf asphaltenes. The weight average nolecular weights were estimated from the relative intensity at zero angle. If the molecular weights determined by vapor pressure osinometry are taken as the molecular weights of the unassociated

\section{TABLE 3}

Small angle $X$-ray scattering results tor $0 P C$ fractioned coal-derived aspi-altenes in pyridiue and in a mixture of solvents at concentration of 10 wt. 5 at $70^{\circ} \mathrm{F}$

\begin{tabular}{|c|c|c|c|c|c|}
\hline & GPC-1 & GPC-2 & GPC-3 & GPC-4 & GPC-5 \\
\hline \multicolumn{6}{|l|}{ Sample in pyridine } \\
\hline $\begin{array}{l}\text { Radius of gyration }-A \\
\text { Spherical diam. }-A \\
\text { Integrated intensity, } Q_{0} \cdot 10^{*} \\
\text { Vol. fraction scattering, }(\Delta V / V)+10^{2} \\
\text { Fraction asphaltene sample scattering } \\
\text { Mol. wt. - vapor presgure osmometry } \\
\text { Mol. wt. - abs. X-ray intengity }\end{array}$ & $\begin{array}{c}14.8 \\
38.3 \\
21.3 \\
3.39 \\
0.42 \\
653.0 \\
1844.0\end{array}$ & $\begin{array}{c}12.9 \\
33.4 \\
16.7 \\
2.56 \\
0.32 \\
588.3 \\
1276.8\end{array}$ & $\begin{array}{c}10.7 \\
27.6 \\
9.54 \\
1.52 \\
0.19 \\
\mathbf{4 0 0 . 5} \\
\mathbf{5 2 8 . 3}\end{array}$ & $\begin{array}{c}\mathbf{8 . 3} \\
21.4 \\
5.72 \\
\mathbf{0 . 9 1} \\
0.11 \\
285.9 \\
274.3\end{array}$ & $\begin{array}{r}8.7 \\
22.6 \\
2.92 \\
0.46 \\
0.06 \\
221.9 \\
169.1\end{array}$ \\
\hline \multicolumn{6}{|l|}{ Sample in solvent mixture* } \\
\hline 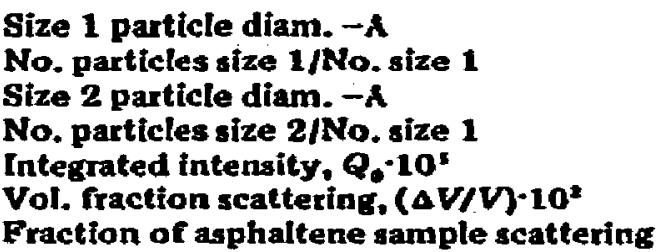 & $\begin{array}{r}29.8 \\
1.0 \\
98.8 \\
0.08 \\
27.50 \\
\mathbf{3 . 6 6} \\
0.46\end{array}$ & $\begin{array}{r}\mathbf{3 5 . 3} \\
1.0 \\
\mathbf{9 8 . 8} \\
0.07 \\
22.80 \\
\mathbf{3 . 0 4} \\
0.38\end{array}$ & $\begin{array}{r}32.9 \\
1.0 \\
89.4 \\
0.09 \\
13.20 \\
1.76 \\
0.22\end{array}$ & $\begin{array}{c}32.9 \\
1.0 \\
89.4 \\
0.13 \\
6.97 \\
0.93 \\
0.12\end{array}$ & $\begin{array}{r}32.9 \\
1.0 \\
\mathbf{8 9 . 4} \\
0.09 \\
\mathbf{3 . 3 8} \\
0.45 \\
0.06\end{array}$ \\
\hline
\end{tabular}

* Solvent mixture is 90 wt.\% tetralin, 2.5 wt.\% m-cresol, 7.5 wt.\% r-picoline. 

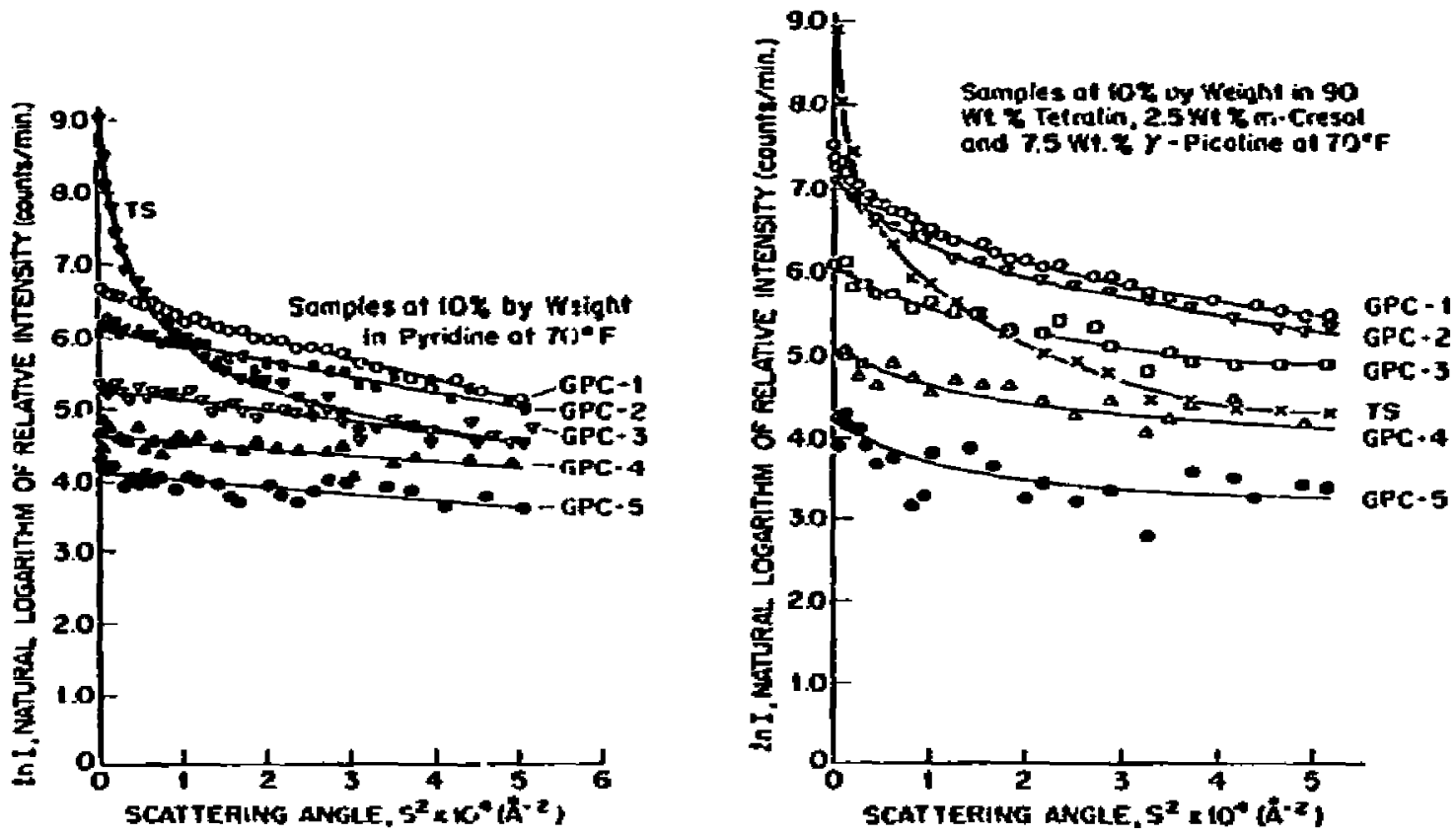

Fig. 7. Variation betwen the OPC fractions and the ariginal sample when disparsed in pyridine at concentrations of $10 w t, \%$ at $70^{\circ} \mathrm{E}$.

Fig. 8. Variation betwsen GPC fractions and the original sample when dispersed in a mix* ture of 90 wt.\% tetralin, 2.5 wt.\% m-cresol and 7.5 wt.\% $\gamma$-picaline at concentrations of 10 wt.g at $70^{\circ} \mathrm{F}$.

inolecules, then an average of 5 GPC-1 molecules associate to form $\sim 38 \mathrm{~A}$ particles and an average of 4 GPC-2 molecules associate to form $\sim 33.4 \mathrm{~A}$ particles.

When dispersed in a mixture of 90 wt.\% tetralin, 2.5 wt.\% m-cresol and 7.5 wt.\% $\gamma$-picoline, the GPC fractions form polydispersed systems. In each the particles were bimodally distributed with the preponderance of particles being the smaller of the two sizes. Tetralin is not as good a solvent as pyridine, $m$-cresol or $\gamma$-picoline and would be expected to permit the clustering of a few of the 30-36 A particles into 89-99 A particles. The Van der Waals attraction between the smaller particles would exceed the solvation repulsion of the solvent molecules. The fraction of the sample scattering $X$-rays is in each case higher in the solvent mixture than in pyridine.

\section{GPCA fraction in pyridine at iifferent concentrations}

Scattering data are given in Fig. 9 for the GPC-4 fraction dispers $-d$ in pyridine at concentrations of $4,10,15$ and 22 wt.\%. Mie scattering is apparent in the $4 \mathrm{wt. \%}$ solution where the relative scattering intensity is 


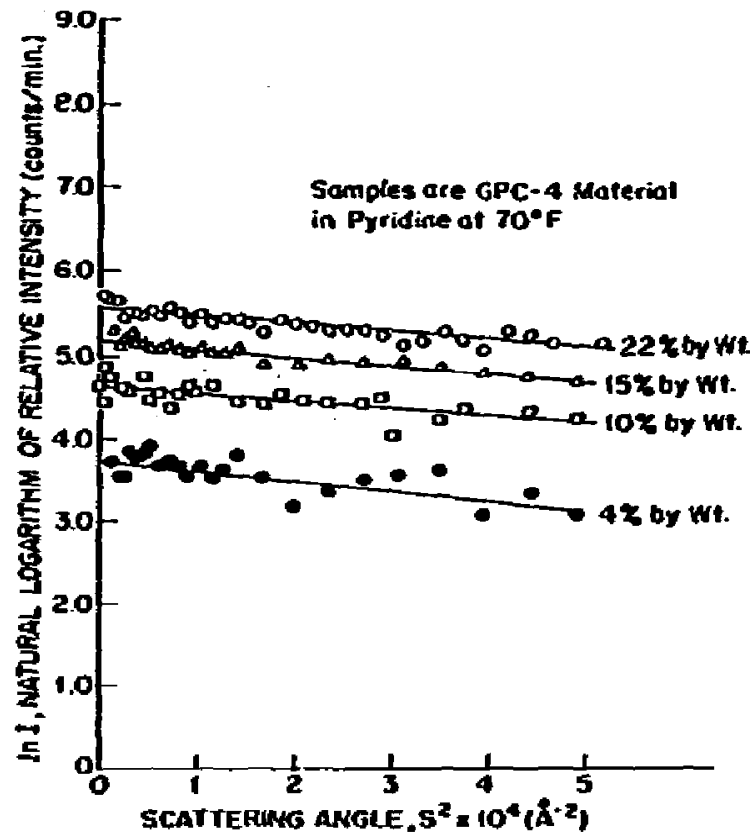

Fig. 9. Effect of the concentration of the GPC-1 fraction In pyridine at $70^{\circ} \mathrm{F}$.

\section{TABLE 4}

Small angle $X$-ray scattering results for asphaltene fraction GPC-4 in pyridine at different concentrations at $70^{\circ} \mathrm{F}$

\begin{tabular}{|c|c|c|c|c|c|c|}
\hline $\begin{array}{l}\text { Conc. } \\
\text { wt.s }\end{array}$ & $\begin{array}{l}\text { Conc. } \\
\text { yol } \%\end{array}$ & Solvent & $\begin{array}{l}\text { Rad. Eyration } \\
\text { (A) }\end{array}$ & $Q_{0} \cdot 10^{3}$ & $(\Delta V / V) \cdot 10^{*}$ & $\begin{array}{l}\text { Fraction } \\
\text { GPC-4 } \\
\text { seattering }\end{array}$ \\
\hline $\begin{array}{r}4 \\
10 \\
16 \\
22\end{array}$ & $\begin{array}{r}3.15 \\
7.97 \\
12.08 \\
18.12\end{array}$ & $\begin{array}{l}\text { Pyridine } \\
\text { Pyridine } \\
\text { Pyridine } \\
\text { Pyxtdine }\end{array}$ & $\begin{array}{r}10.7 \\
8.3 \\
9.1 \\
8.4\end{array}$ & $\begin{array}{r}2.08 \\
6.47 \\
6.67 \\
12.71\end{array}$ & $\begin{array}{l}0.36 \\
1.12 \\
1.50 \\
2.20\end{array}$ & $\begin{array}{l}0.11 \\
0.14 \\
0.12 \\
0.12\end{array}$ \\
\hline $\begin{array}{l}10 \\
15 \\
22\end{array}$ & $\begin{array}{r}7.89 \\
11.90 \\
17.72\end{array}$ & $\begin{array}{l}\text { Mixture* } \\
\text { Mixture } \\
\text { Mixture }\end{array}$ & $\begin{array}{r}12.3 \\
10.2 \\
9.1\end{array}$ & $\begin{array}{r}6: 93 \\
10.11 \\
13.63\end{array}$ & $\begin{array}{l}1.20 \\
1.75 \\
2.36\end{array}$ & $\begin{array}{l}0.15 \\
0.15 \\
0.13\end{array}$ \\
\hline
\end{tabular}

- Solvent mixture is 90 wt.\% tatralin, 2.5 wt.9 m-cresol, 7.5 wt.9 $\gamma$-picolice.

relatively low. From the analyzed results in Table 4 , it can be seen that the fraction of the sample scattering $X$-;ays is nearly constant. One explanation is that only certain molecules are associating. When the concentration is doubled the number of particles double but the fraction scattering remains constant. The other explanation is that multiple scattering leads to an under- 
estimate of the particte diameter and fraction scattering. The weight average molecular weight at the four concentrations was essentially constant, beijg $274 \pm 10$. When the samples are dispersed in the mixture of solvents the particle diameters and fractions of the samples" scattering $X$-rays both increase.

\section{GPC-4 fraction in different soluents}

Scattering data are presented in Fig. 10 for the GPC-4 fraction dispersed in five solvent systems at a concentration of $10 \mathrm{wt} . \%$. The relative scattering intensities are inversely proportional to the solvation repulsion of the solvent. The analyzed results are given in Table 5. With the exception of pyridine, the GPC-4 material formed potydispersed systems in the solvents. This can in part be attributed to the variety of compound classes in the sample. THF can solubilize hydrogen bonding molecules but has little influence on $\pi-\pi$ bonding molecules.

\section{Effect of ultrasonic agitation}

Runs were made with Tsf material at a concentration of 1 wt.\% in pyridine to assess the effect. of mechanical stress on the colloidal system. In one case the sample was allowed to remain at rest for at least $74 \mathrm{~h}$ and in the other the sample was ultrasonically agitated and inmediately placed in the
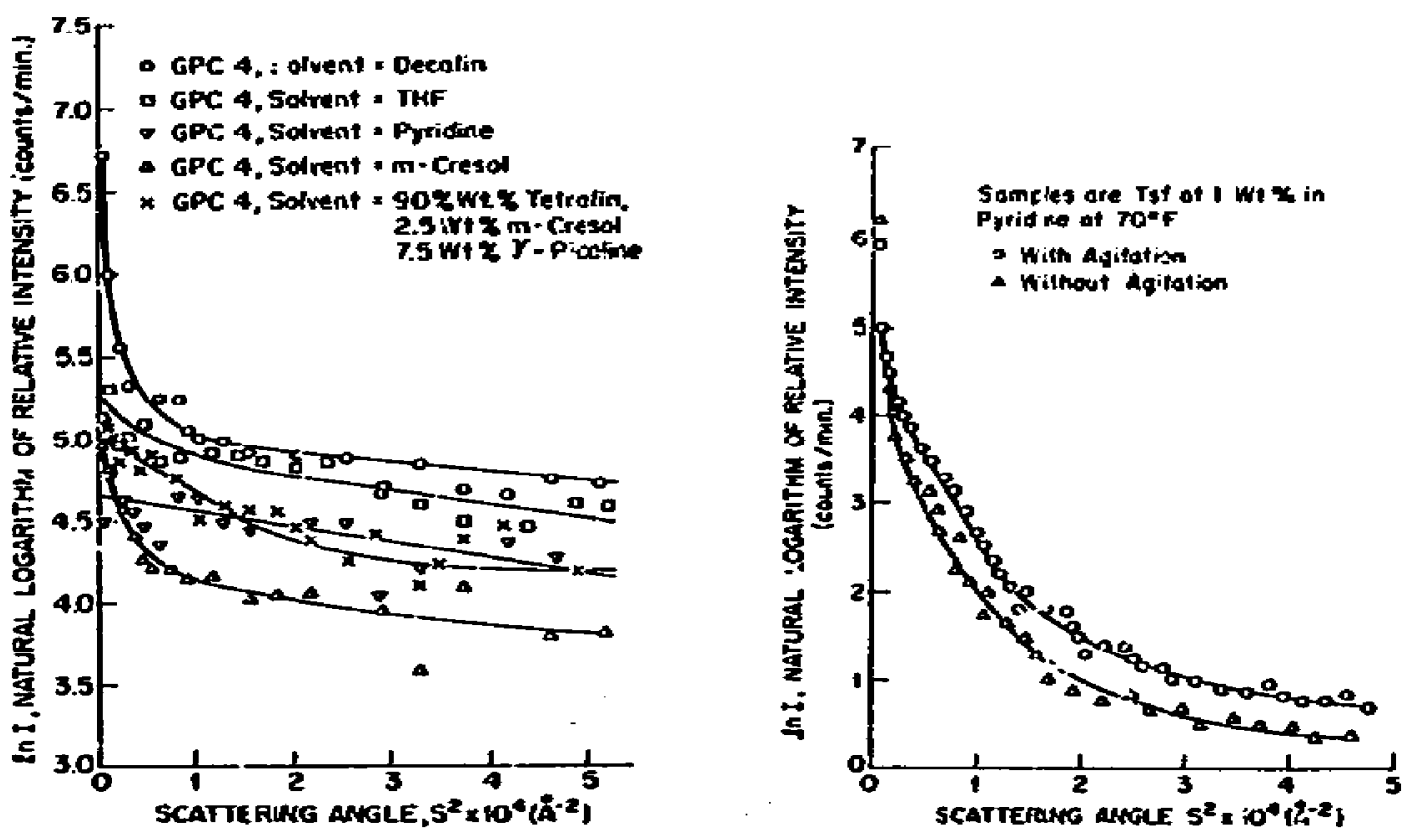

Big. 10. Effect ui solvent on GPC-4 fraction at 10 wt. $x$ solutions, at 70 F.

Fig. 11. Effect cif agitation on the relative scattering intenatiy of Tse in pyridine dt a concentration of $1 \cdot \mathrm{Nt} . \mathrm{S}$ at $70^{\circ} \mathrm{F}$. 
TABI.E 5

Small sngle X-ray scattel ing cesults for asphaltene fraction GPC-4 in various solvents at a concentration of 10 wt.. at $70^{\circ} \mathrm{F}$

\begin{tabular}{|c|c|c|c|c|c|}
\hline Solvent & Decalin & THE & Mixture & Pyridine & m-Cresol \\
\hline 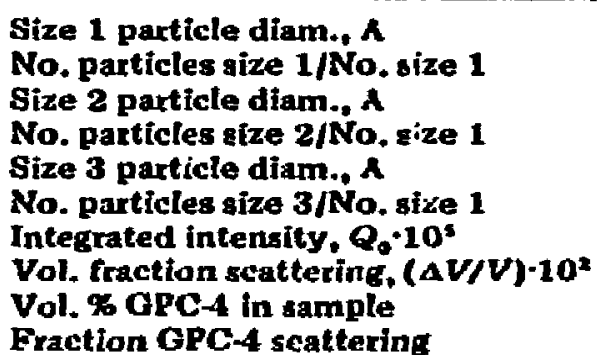 & $\begin{array}{c}29.8 \\
1.0 \\
98.8 \\
0.08 \\
147.4 \\
0.02 \\
9.61 \\
1.67 \\
7.4 \\
0.21\end{array}$ & $\begin{array}{c}29.8 \\
1.0 \\
98.3 \\
0.04 \\
- \\
9.09 \\
1.37 \\
7.3 \\
0.19\end{array}$ & $\begin{array}{c}30.5 \\
1.0 \\
- \\
- \\
6.93 \\
1.20 \\
7.9 \\
0.15\end{array}$ & $\begin{array}{c}21.4 \\
1.0 \\
- \\
- \\
\\
6.23 \\
0.90 \\
8.0 \\
0.11\end{array}$ & \begin{tabular}{c|}
32.9 \\
1.0 \\
89.4 \\
0.12 \\
133.4 \\
0.01 \\
4.18 \\
0.61 \\
8.4 \\
0.07
\end{tabular} \\
\hline
\end{tabular}

TABLE 6

Effect of agitation on small angle $\lambda$-ray scattering by a high moleculet weight asphaltene fraction at a concentration of 1 wt. $\%$ in Pyridine at $70^{\circ} \mathrm{F}$

\begin{tabular}{|c|c|c|}
\hline & $\begin{array}{l}\text { With } \\
\text { agitation }\end{array}$ & $\begin{array}{l}\text { Without } \\
\text { agitation }\end{array}$ \\
\hline 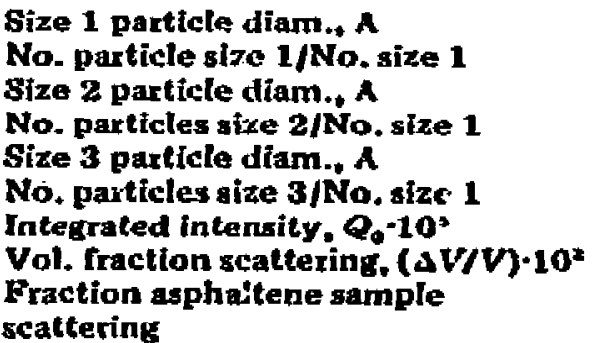 & $\begin{array}{l}29.8 \\
1.0 \\
89.4 \\
0.087 \\
147.4 \\
0.020 \\
0.33 \\
0.0084 \\
0.0105\end{array}$ & $\begin{array}{c}29.8 \\
1.0 \\
89.4 \\
0.079 \\
147.4 \\
0.005 \\
0.063 \\
0.0016 \\
0.0020\end{array}$ \\
\hline
\end{tabular}

cell and the scattering curve obtained. The restilis shown in Fig. 11 indicato a higher relutive intensity from the ultrasonically agitated sample. The particle size distribution and the volume fraction scattering results for the two systems are ziven in Tabie 6. Although the peaks in the particle size distributions ane thr: same, approximately five times, more of the Tsf material is scattering $X$-rays in the agitated sample. There is also more of the $147.4 \mathrm{~A}$ particles rel itive to the $79.8 \mathrm{~A}$ particles in the agitated sample. When the Tsf is allowed to rest, the larger colloidal particles apparently form a floc of the order of 10C0 \& or more. The floc will ceuse the Mie scattering that is observed and will reduce the number of particles scattering $X$-rays in the small angle range. When the agitated sample is allowed to rest for $24 \mathrm{~h}$, the intensity of scattered $X$-rays drops aysin to the lower value. - . 


\section{CONCLUSTONS}

The pbysical state of coal-derived liquid-solvent systems depends upon the balance of forces between molecules and associations of molecules at the temperature and shear state of the systems. At the molecular scale, the strongest forces of attraction are the $\pi-\pi$ bonding attractions between polyaromatic molecules. The force of attraction is usually greater when the polyaromatic molecules contain heteroatoms, such as phenolic oxygen and ring nitrogen atoms, which can hydrogen bond.

In all the systems studied, most of the colloidal particles were spherical with diameters in the range of $22-38 \mathrm{~A}$. These particles were formed by inter-molecular association of 3 to 5 polyaromatic molesules. The size of the particles formed by internolecular association and the fraction of molecules associating into particles is closely related to the number average moiecular weight of the unassociated molecules as shown in Fig. 12. Since the asphaltene and preasphaitene fractions are highty aromatic, the number of $\pi-e l e c-$ trons in an individual molecule is also closely related to the molecular weight.

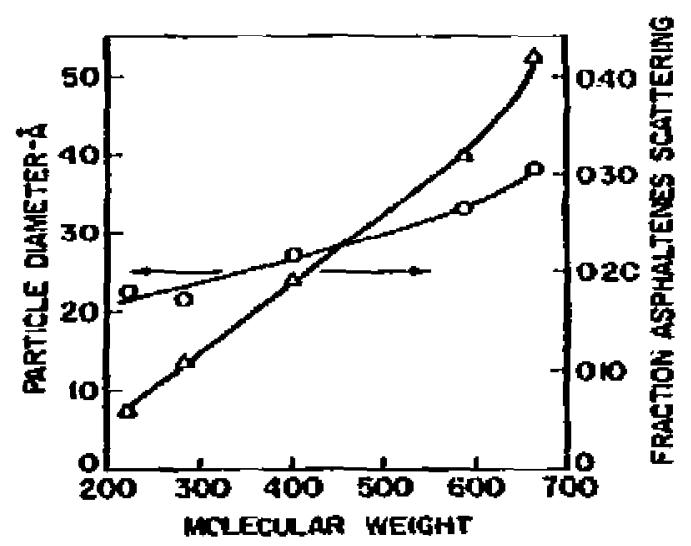

Fig. 12. Variation of the micelle dlameter and fractlon of the sample scattering $X$-rays with the number average moleculs $x$ weight of the unassociated molecules in the 6 GPC fract tons.

Once 3 to 5 molecules associate into a micelle, there appears to be little or no tendency for an isolated molecule to associate with the particle. The particle either has little or no residual capacity to $\pi-\pi$ or hydrogen bond with the molecule, or the molecule has considerably fewer than the average number of $\pi$-electrons and heteroatoms in the particular coal-derived liquid fraction. The solvent plays an important role through solvation repulsion. When dispersed in solvent molecules which are more easily "squeezed out", association of molesules with fewer $\pi$-electrons would be expected, Van der Waals attraction become important and polydispersed systems result. 
The particle-fize distribution data for the polydisłersed systems indicate two or three separate peaks with a unique relationship between the sizes at which the peaks recur. Although the $\pi-\pi$ bonding tendency between particles would b:s expected to drop off sharply, the London-Van der Waals attraction between particles would be expected to increase sharply as the size of the particies increases. The most stable orientation for particles held together by Loncion-Van der Waals attractions would be as in a hexagonal close-packed arrangement as occurs when four 22-38 $\mathrm{A}$ particles cluster as illustrated in Fig. 13 to form an 80-100 A partisle. The shape of the new particle is still approximately spherical. Depending upon the temperature, shear state and the properties of the "liquid" phase, further assijciation could be expectedl to proceed in two ways. Four additional $22-38 \mathrm{~A}$ parrticles could cluster with the 80-100 A particle to form a nominally szherical particle of 130-360 A or four 80-100 \& particles could agglomerate to form a super micelle or floc with a diameter in excess of $4 \pm 0 \mathrm{~A}$. Interestingly, the tendency to form spherical particles was observed by Ho [13] when asphaltenes were jrecipitated from an asphuitene-THF solution on the addition of decalin. Stanning electron micrographs as snown in Fig. 14 show the presence of spheical particles of $3000-4000 \AA$ in diameter.

The limited da:a on the effect of concentration for the GPC-4 fraction shows that the fraction of the sample scattering $X$-rays is roughly independent of the concentration. Although this might appear to violate ther-

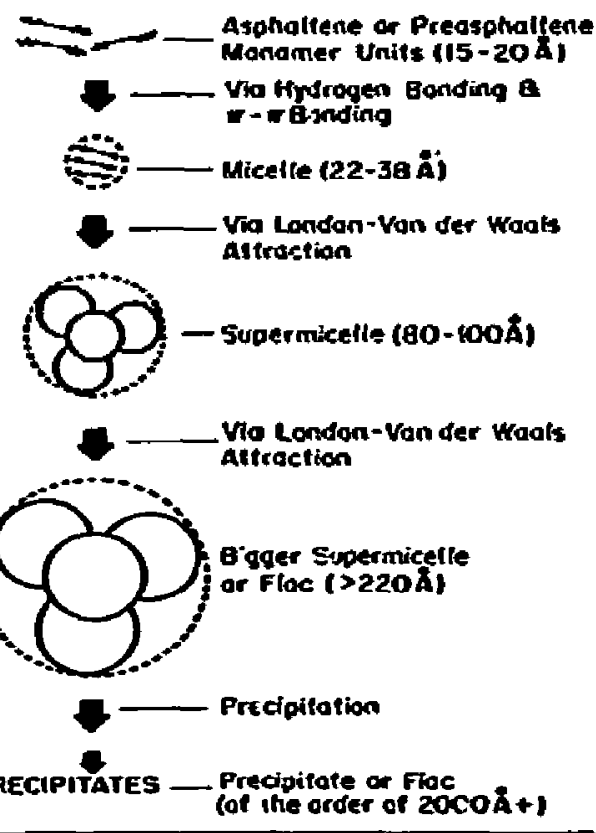

Fit. 13. Proposed sssociation mechanism of asphaltenes and pre-asphaltenes in solution. 


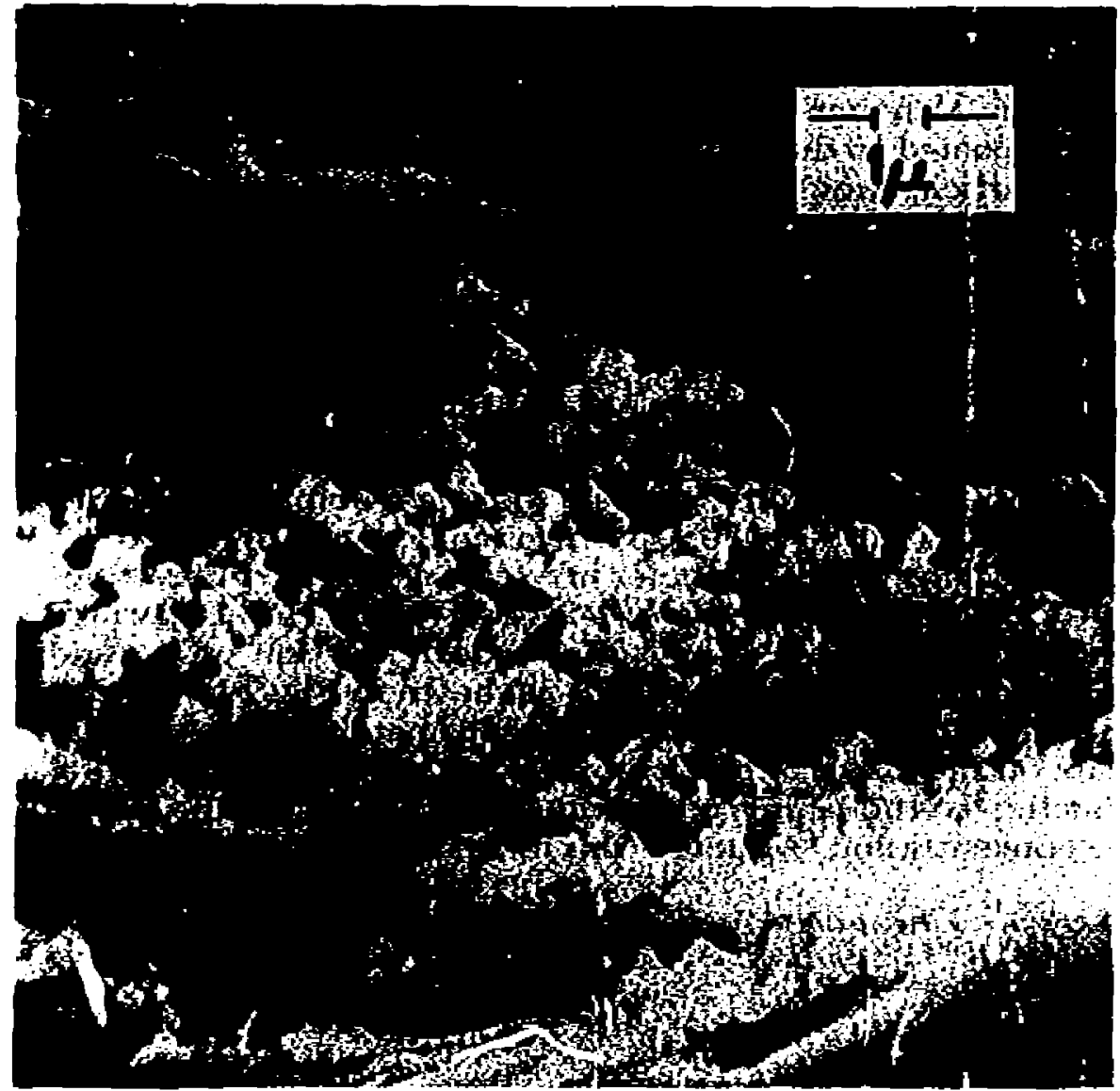

Fig. 14. Scanning electron micrograph at approximately 5000x of anphattenes precipitated from an asphaltene-THF solution on the addition of decalin.

modynamic principles, this GPC fraction is a mixture of compounds with various tendencies to associate. The molecules which do have a strong tendency to associate, will, regardless of the concentration. When the concelltration is increased, there is an increase in the solvation repulsion tendency through the presence of individiai coal-derived liquid molecules in solution.

Floc structures with dimenstons in excess of $1000 \mathrm{~A}$ form when asphaltene-solvent systems are allowed to rest for extended periods. 'The existence of floc structures can be observed via Mie scattering and the structures are destroyed by mechanical shear as in ultrasonic agitation. Upon extended rest the floc structure returns.

\section{ACKNOWLEDGEMENTS}

The research reported here was sponsored under the U.S. Department of Energy Contact EX-76-5-01-2550. 


\section{RE.'BHENCES}

1 D.E. Briggs, D.V. Addington and J.A. McKeen, Coal IV, CEP Tech. Manual, 1978.

2 D.E. Briggs, Electrostaties in Non-Aqueous Liquid Particle Separations, (in press). Proceedings of Fine Particle Society Fall Meeting, 1980, Hemisphere Publ. Corp.

3 L.Ax. Snyder, J. Phys. (:hem., 67 (1963) 2344.

4 B. S.-Y. Ho, Particle Size Configuration Determination of Coal-Derived Asphaltenes and Preasphaltenes in solution by Small Angle X-ray Scattering. Ph.D. Diss., Univ. of Michigan (1930).

5 P.W. Schmidt and R.W. Hendricks, Acta Phys. Austraiaca, 26 (1967) 97.

6 P.W. Schmidt and R.W. Headricks, Acta Phys. Austraiaca, 37 (1973) 20.

7 A. Guinier, G. Foumet, C.B. Walker and K.L. Yudowitch, Small Angle Scattering of X-rays, Wiley, New York, 1955.

8 W.W. Beeman, P. Kaesherg, Anderegg and Webb, Handbuch der Physik, 32, Springer-Verlag, Berlir;, 1957.

9 M.H. Jellineh, E. Solomon, and I. Fankucken, Ind. Eng. Chem. Anal. Ed., 18 (1966) 172.

10 G.G. Vonk, J. Appl. Crystallogr., 9 (1976) 433.

11 O. Kratky in : T.A.V. Butles, H,E. Huxley and R,E, Zirkle (Eds.), Progress in Biophysics and Molecular Biology. 13, Pergamon Press, New York, NY, 1963.

12 O. Kratky. "Application of the Lupolen Platelet Designated with $16 / 12$ as a Calibration Sample for the Uetermination of the Absolute Intensity and of the Primary Energy in the Case of Slit-Collimation," unpublished paper, (1977).

13 D.E. Briggs, B. Ho, P.A.S. Smith, et a:." "Physical and Chemical Behavior of Liquefied Coal in Solids Separation," $C$;.S. DOE Report IF-2550-8, Aug., $19 \% 9$. 